\title{
Network-based Blended Teaching Design in English Reading Course
}

\author{
Manli Lu \\ Department of Foreign Languages Beijing Wuzi University, Beijing, China \\ nancy-manli@163.com
}

\begin{abstract}
This paper aims to put forward a network-based blended teaching design for English Reading course based on blended learning theory. Four procedures have been presented to demonstrate the design of blended teaching and the outstanding advantages of this design are expounded in this paper.

Keywords: Blended Learning; E-learning; Teacher-centered; Student-centered; Cooperative Learning
\end{abstract}

\section{Introduction}

With the growing popularity of multimedia and network technology, the traditional way of teaching English reading has been unable to meet the needs of English learners. Therefore, network-supported learning flourished. Under the network environment, learners can learn information without the constraints of time and space; besides, the on-line data are rich, flexible, and easy to be accepted by the learners, network also provides learners with an open, realistic language environment [1]. It makes the students learn knowledge more initiatively, but its disadvantages should not be overlooked. In our teaching practice, teachers realized that traditional classroom teaching and online teaching both have their pros and cons. We can not put one-sided emphasis on any kind of them. One teaching model can not be replaced simply by another one. Single teaching model can not adapt to the needs of the development of college English reading teaching. Therefore, educators began to consciously blend the traditional classroom teaching with online teaching to improve the teaching of our college English reading course. However, they did not achieve any tangible results. The reason was the teachers just combined the classroom teaching and learning environment with the online teaching environment. They just simply changed the reading instruction to another form of pictures, sound, video and multimedia to the students in order to attract the attention of students. But the teaching process is still the teachers to "teach", and the teachers are also in the dominant position in one class. The students were not the main body of the class. Therefore, we should not just blend the teaching environments or the mediums of instruction for the blended learning in our college English reading course. Blended learning should be an integration of multi-angle and all aspects. More should be blended at the right time with the right content.

\section{An Overview of Blended Learning}

Since the late 1980s, with the booming of modern information technology based on the multimedia computer and network communication technology, one digital learning (E- learning) has been sweeping the globe. Following this, there have a lively discussion about whether the traditional classroom teaching should be replaced by the E-learning. While summing up the results of the E-learning teaching we found that E-learning had its shortcomings. Under this dilemma, with the technological innovation we blend the faceto-face teaching with the on-line environmental learning, and the Blended Learning came into being [2]. Michael Orey gives the definition of blended learning from the following three aspects: from the point of view of the learners blended learning means a match of the existing knowledge and learning styles to a new educational resources; from teachers' point of view, blended learning is a reasonable organization and distribution of a variety of educational resources; and from the point of view of education managers, blended learning is an economical and efficient management and distribution of educational resources[3]. Dziuban Hartman claims that the blended learning should be thought as a teaching method, and this teaching method is an effective combination of the classroom teaching and the active IT support online learning[4]. The concept of Blended Learning has been the subject to domestic scholars' attention since it is introduced by Professor He Kekang in 2003. He said Blended Learning is a way which combines the strengths of the traditional learning with the advantages of E-learning, that is, it not only pays attention to the teachers' guiding, inspiring and monitoring role in the teaching process, but also fully embodies the initiative, enthusiasm and creativity of the students in the learning process [5]. According to the definition on Blended Learning from domestic and foreign experts and scholars, we can sum up that the so-called blended learning actually means the blending of different learning styles and teaching elements. It re-organizes our teaching resources using the advantages of traditional classroom learning and the E-learning mode so that the two modes can complement with each other. It not only stresses the leading role of teachers, but also stresses the dominant position of students in the teaching process, and eventually achieves our goal of improving the teaching effectiveness.

\section{Network-based Blended Teaching Design in English Reading Course}

In traditional teaching, teachers play a leading role in the classroom; while the main body status of the students is often neglected. The teachers are more dominant, the students are more passive. This is a "teacher-centered" educational thought. 
However, the opinion of the western constructivism is just the contrary - it only emphasizes "student-centered" thought, and it tends to go to the other extreme ignoring the leading role of teachers [5]. We believe that the correct form of ideological education should embody these two, combined, that is, not a "teacher-centered" or "student-centered," but a way to give full play to the leading role of teachers and main body role of the students in learning. This paper tries to put forward a blended teaching design in college English reading course based on the blended learning theory and the status quo, and its guiding ideology is: we should not only play the leading role of teachers in the teaching process, but also fully play the dominant position of the students in the learning process. The designing is just as the following, divided into four procedures:

\subsection{Procedure One: Knowledge Learning}

In this procedure, teachers need to teach the language points of the textbooks. Language learning can not be separated from the learning of the basics. Our traditional "teacher-centered" mode has its advantages where the teachers can teach language points to students systematically. Blended teaching design takes the advantages of traditional teaching, and it integrates traditional teaching with IT efficiently during the process of implementation of the teaching, and makes full use of the advantages of the network, and it makes the teaching process become more interesting. Teachers should create the topic-related situations by choosing suitable teaching media, such as pictures, sound and video according to the characteristics of the students so that they can mobilize the students' interest in learning and stimulate their thirst for knowledge. In addition, through the creation of scenarios, teachers can make the students be clear for their reading theme so that they can smoothly come to the next step of the teaching and learning activities and reach the teaching aims of reading.

\subsection{Procedure Two: Completing the Reading Task with the Help of Network}

After the teaching of the reading theme, teachers should present the reading tasks to students so that they can have a purpose and direction in the reading process. On one hand, due to the complicated network resources, teachers should guide students how to use the resources to obtain information, analyze information and to help students find relevant information within a limited time [6]. The teachers can also provide students with several websites related to the teaching theme so that the students can search and read the relevant information in a certain range. On the other hand, teachers should allow students to know clearly about learning steps, learning strategies and presentation of the outcome of the task to ensure the smooth progress of the teaching of reading.

In this procedure the tasks of the students are divided into two sides. First, teachers specify topic-related passages to each student to read. The students should finish the comprehensive questions or other assignments. Second, teachers set a topicrelated complicated task to each group of students, and each group complete the task through their teamwork of group discussions, searching information on the Internet and etc..

\subsection{Procedure Three: Group Presentation}

For each group, the teacher asks them to give a presentation after their completion of the reading task. And during the presentation the students should have some interaction with each other. They should give group peer assessment, and finally the teacher should give some comments. This procedure is a kind of cooperative learning strategies. Cooperative learning is an effective supplement for students' independent learning. On the basis of independent learning, students begin to cooperate and exchange. Teachers provide good environment for collaborative learning, and timely participate the exchange, regulation and guidance. This process is not only an enhanced function to students' independent learning, but also an improvement of the ability of students to use the language. Finally, the teachers should summarize and review the completion of the task, point out the bright side as well as the weak points, give feedback to the students timely.

\subsection{Procedure Four: Construction of Significance of this Blended Teaching Design}

The last procedure of the "blended" instructional design is the analysis of the results of teaching and learning based on students' electronic records online and their questionnaires. We form a developing teaching evaluation, both to help teachers understand the situation of the students' learning, but also help promote the ability of students' independent learning [7]. Developmental evaluation not only pays attention to the students 'academic' performance, but also discovers students' multifaceted potential. It helps students build their selfunderstanding and self-confidence, and at the same time it pays attention to the educational function of evaluation to promote the development of the students from their original level. According to the results of the evaluation, the teachers can not only understand the students' own learning progress, and urge them to learn, but also they can have some reflection on their teaching. Through this they can improve teaching methods, adjust the progress of teaching, and strengthen the improvement of weaknesses in students' knowledge.

\section{The Advantages of Blended Teaching Design in College English Reading Course}

\subsection{Reflecting the Educational Thought that the Teacher the} Leading Role, the Student the Main Body

In this blended teaching design, the role of teachers in the teaching process is various. They are not only the conveyer of the knowledge, but also a guide who lead the students to think about issues, and at the same time a designer of the activities, a facilitator and supervisor of the learning process. Students are the recipient of the language, and at the same time the explorer of the real life world, the thinkers who are responsible for their own learning. While the classroom is the place where the ideological collision takes place between teachers and students, the students and the students. Language then 
becomes a carrier of ideas in the process of expression of ideas, and during the expression of their ideas students master the language. The blended reading course teaching design fully reflects the "dual master" educational thought, that is, the teacher is the guide while the student is the main body in the teaching process [2].

\subsection{Ensuring the Appropriateness of the Reading Material}

The choice of the reading material is crucial in our teaching of English reading. The reading material in the network multimedia environment can be described as varied and complicated, then how can we select the appropriate material to read? The guidance of our teacher is very important. It is important for the teachers to select the reading material and determine the reading tasks for the students to complete in the Procedure One. Such as for the English majors, teachers had better select some works by the English native speaker, or some original English texts for higher level readers. The reading material should meet the levels of the students. In some English learning websites there are many ready-made reading materials for the various stages of English proficiency learners. In this new blended teaching design, teachers select the reading material according to the students' levels of English and this ensures the appropriateness of the choice of reading material.

\subsection{Making the Reading Content Contextualized}

Because this design is based on the network, in Procedure One, the analysis of the background and language points of the text, teachers can make full use of the network to showcase different types of articles of a variety of genres and styles. Teachers can make full use of the network to reflect the history of Eastern and Western customs, characters environment, and introduce our social scientific knowledge. Teachers can carry out their carefully designed interaction with the help of the internet. Under this network environment the interaction of the students exists mainly in the interaction with the computer, with teachers, with students and with English native speakers [8]. Students and students expand a discussion on a topic of literature, history, geography or other disciplines through the internet. Students exchange their opinions in a meaningful real, natural language input. They enhance the amount of reading through the real or virtual reality learning contexts. In this network-based design they enhance their interest of reading so as to further enhance their level of English language learning.

\subsection{Developing Students' Task-based Cooperative Learning and Research Learning}

The characteristic of interaction of the network environment provides an open exchange environment beyond time and space between our teachers and students. Free and non-binding network exchange can fully encourage the participation of students and greatly stimulate the imagination and creativity of them. The students use the target language to discuss, exchange, and conduct a joint inquiry-based learning to cultivate the ability to explore during the completion of their reading tasks. Learning via the Internet meets the characteristics of students. It can stimulate students' interest in the language learning. It tries new ways and methods of learning English, and develops the students' ability of independent learning [9]. Data search process itself is a process of widely reading. The process of browsing on the network of the students is also a training of reading skills (fast reading, skimming, guessing the word and etc.). Online discussions and articles is a formation of the writing process, students focus on practicing the word, expression and basic sentence of the unit prompted by the electronic bulletin board online. In order to express views and opinions freely in the presentation, the students repeatedly practice their pronunciation and basic tone to improve the fluency of their English. And the students' lecture trains their listening. Closely linked learning procedures make the students improve their ability of language application and fully exert their potential.

\section{Conclusion}

In recent years, with the gradually acceptance of the new concept of Blending Learning, more and more teachers recognize that "student-centered" instructional design has its own outstanding advantages (conducive to promoting selfexploration and innovation spirit of the students), but it also has its own drawbacks (not conducive to conveying knowledge systematically); while the "teacher-centered" design is exactly the opposite. Therefore we tend to blend these two types, that is, the blended teaching design. This teaching design breaks the single mode of traditional teaching in teaching methods and means, extends the classroom from the time and space and creates a visualized, diverse, lively classroom environment. It is a kind of multi-faceted and three-dimensional information input which is conducive to our language teaching. It blends the leading role of the teachers with the main body role of the students. It can not only reflect the teachers' guiding, inspiring and monitoring role in the teaching process, but also fully embody the students' initiative, enthusiasm and creativity as a main body in the learning process. It creates a fine language teaching and learning atmosphere so that we can reach our best teaching result.

\section{Acknowledgment}

Many people gave me much help during this paper writing. Many thanks to my colleagues in our English department, and many thanks to my family, without them I couldn't have finished the important part of my thesis. They deserve my sincere acknowledgement.

\section{References}

[1] Y. Q. Shen, "The possibilities of teaching online English Extensive Reading in English major", Journal of Yulin Teachers College, 4, pp.108110,2004

[2] S. W. Zong, "Research of web-based blended teaching design and application", China Master's Theses Full-text Database, Hebei University, pp. 1-6, 2010

[3] M. Orey, "Definition of blended learning" http: / /www. arches. uga. edu /mikeorey /blended learning /

[4] Dziuban, et al. "Blended learning". http: / / www. educause.edu / ir/ library /pdf/ERBO407 
[5] K. K. He, "New development of the theory of educational technologyfrom the perspective of Blending Learning", Journal of National Academy of Education Administration, 9, pp.37-48, 2005

[6] J. X. Qu and D. Yang, "The implementation and assessment of the 'Internet+classroom' blended teaching model in college English", Northwest Medical Education, 2, pp.358-360, 2011
[7] Y. Xie, "Blended teaching design in comprehensive English course with the support of Internet", Teaching and Management, 12, pp.130-131, 2010

[8] L. N. Xing and H. J. Zhao, "Thoughts on the reform of reading-teaching for English majors based on multimedia and Internet", Social Sciences Education, 8, pp.115-116, 2011

[9] W. Fan and S. Y. Xu, "On network-based college English reading classroom teaching model”, Overseas English, 11, pp.26-27, 2010 